\title{
PERANCANGAN PENGUAT AWAL MENGGUNAKAN TABUNG HAMPA PADA ARAS TEGANGAN RENDAH
}

\author{
Matias H.W. Budhiantho, Gunawan Dewantoro, Demas Sabatino \\ Program Studi Teknik Elektro, Fakultas Teknik Elektronika dan Komputer \\ Universitas Kristen Satya Wacana \\ e-mail: gunawan.dewantoro@staff.uksw.edu
}

\begin{abstract}
Abstrak-Penguat tabung hampa telah dikenal sebagai penguat audio dengan sifat soft-clipping, dan tidak seperti penguat transistor yang bersifat hard-clipping. Tabung hampa umumnya merupakan suatu komponen aktif yang bekerja pada aras tegangan tinggi (ratusan volt), namun pada aras tegangan tinggi penguat tabung membutuhkan transformator keluaran untuk menurunkan aras tegangan isyarat keluaran. Penelitian ini bertujuan untuk merancang penguat awal dengan menggunakan tabung hampa pada tegangan kerja 12 VDC. Untuk merancang untai tabung hampa pada aras tegangan rendah, telah dilakukan pengukuran untuk mendapatkan grafik karakteristik trioda 12AT7. Untai tabung hampa direalisasikan dengan topologi katoda bersama yang dikaskade dengan anoda bersama. Dari hasil pengukuran didapatkan spesifikasi penguat awal yaitu impedansi masukan sebesar $1.11 \mathrm{M} \Omega$, impedansi keluaran $3.5 \mathrm{k} \Omega$ pada kanal kanan dan $3.2 \mathrm{k} \Omega$ pada kanal kiri, THD maksimal terjadi pada frekuensi $4 \mathrm{kHz}$ di kanal kanan yaitu sebesar $1.7 \%$, bati tegangan 20,08 dB pada kanal kanan dan $20 \mathrm{~dB}$ pada kanal kiri, sensitivitas $212 \mathrm{mVrms}$, aras keluaran maksimal $2 \mathrm{Vrms}$, tanggapan frekuensi yang rata pada rentang $60 \mathrm{~Hz}-20 \mathrm{kHz}$ dengan fluktuasi $\pm 0.5 \mathrm{~dB}$. Penguat awal ini dapat digunakan secara bergantian dalam dua ragam, yaitu ragam linier dan ragam cacat berupa efek flanger.
\end{abstract}

Kata Kunci : Penguat Awal, Tabung Hampa, Mode Linear, Mode Distorsi

\begin{abstract}
Vacuum tube amplifiers have been known as softly-cliping audio amplifiers, as opposed to solid-state based amplifiers which exhibit hard-cliping properties. However, vacuum tubes are operated in high voltage level. Meanwhile, in order to work in low voltage level, a vacuum tube amplifier must employ step down transformers that leads to complexity. This study aims to make use of vacuum tubes in a preamplifier working on $12 \mathrm{VDC}$ level. First, several measurements were done to obtain graphics of characteristic of triode 12AT7 in low voltage level. Common-cathode topology was cascaded with a common-anode topology to realize such amplifier. The results show that the preamplifier has an input impedance of $1.11 \mathrm{M} \Omega$, output impedance of $3.5 \mathrm{k} \Omega$ for the right channel and $3.2 \mathrm{k} \Omega$ for the left channel. Maximum Total Harmonic Distortion of $1.7 \%$ occurs on frequency of $4 \mathrm{kHz}$. Voltage gains of $20.08 \mathrm{~dB}$ and $20 \mathrm{~dB}$ were obtained for the right and left channels, respectively. This pre-amplifier also shows sensitivity of $212 \mathrm{mVrms}$, maximum output level of $2 \mathrm{Vrms}$, and relatively flat frequency response within $60 \mathrm{~Hz}-20 \mathrm{kHz}$ with ripple of $\pm 0.5 \mathrm{~dB}$. This pre-amplifier can be alternatively used in two modes, namely linear mode and distorted mode.
\end{abstract}

Keywords : Pre-amplifier, Vacuum Tube, Linear Mode, Distorted Mode

\section{PENDAHULUAN}

Penguat awal pada dasarnya merupakan perangkat elektronika yang digunakan untuk menguatkan amplitudo tegangan suatu isyarat elektrik. Penguat awal memiliki bentuk isyarat keluaran yang sama dengan isyarat masukannya, dengan skala amplitudo yang dapat diperhitungkan. Agar dapat menguatkan suatu isyarat maka perangkat elektronika memerlukan komponen aktif seperti transistor, op-amp, atau tabung hampa. Pada daerah liniernya, komponen aktif dapat mereproduksi isyarat tanpa cacat. Namun ketika diberi masukan yang melebihi headroom penguat, maka akan terlihat perbedaan dari jenis komponen aktif yang digunakan.

Penguat tabung hampa akan tidak memenggal isyarat di luar ambang batas secara tajam, sehingga ujungnya terlihat membulat, sedangkan pada penguat transistor didapati ujung yang datar dan tajam. Masing-masing disebut dengan soft-clipping dan hard-clipping $[1,2]$. Kedua jenis pemenggalan ini akan 
menghasilkan efek suara yang berbeda, karena mempengaruhi frekuensi harmonisa yang dihasilkan. Hingga saat ini penguat tabung hampa masih banyak digunakan karena kualitas suara dan cacat (distortion) yang dihasilkan oleh soft-clipping sering disebut "hangat" dan menyenangkan [3]. Penguat tabung dapat digunakan untuk mereproduksi isyarat audio dengan akurasi tinggi, atau biasa disebut dengan high fidelity. Hal ini dikarenakan isyarat yang direproduksi oleh penguat tabung seolah-olah memiliki headroom yang tinggi oleh pendengar. Dengan kata lain walaupun isyarat keluaran telah mengalami cacat karena melewati headroom penguat, isyarat tersebut tetap terdengar tanpa cacat.

Penguat tabung memiliki toleransi isyarat masukan hingga $20 \mathrm{~dB}$ di atas headroom penguat, dibandingkan dengan transistor $(10 \mathrm{~dB})$ atau opamp $(5 \mathrm{~dB})$ [4,5]. Tabung hampa umumnya merupakan suatu komponen aktif yang bekerja pada aras tegangan tinggi (ratusan volt), namun pada aras tegangan tinggi penguat tabung membutuhkan transformator keluaran yang berfungsi untuk menurunkan aras tegangan isyarat keluaran [6]. Sehingga saat ini penguat tabung hampa jarang digunakan karena dianggap kurang praktis. Meskipun terdapat tabung hampa yang didesain khusus untuk bekerja pada aras tegangan rendah, namun ternyata tidak menutup kemungkinan bahwa tabung hampa yang biasa bekerja pada aras tegangan tinggi juga dapat digunakan pada aras tegangan rendah [7], walaupun penguat tabung hampa pada aras tegangan rendah dapat menyebabkan rendahnya headroom dan cacat yang tidak terkontrol. Oleh karena itu penulis telah merealisasikan suatu penguat awal yang bekerja pada aras tegangan rendah sehingga memiliki nilai kepraktisan yang selama ini tidak dimiliki oleh penguat tabung hampa. Walaupun bekerja pada aras tegangan rendah penguat awal ini ditujukan untuk mereproduksi isyarat audio tanpa cacat (ragam linier). Penguat awal juga dilengkapi dengan ragam cacat berupa efek flanger, di mana ragam cacat dan linier dapat digunakan secara bergantian dengan memindah saklar (footswitch) yang terdapat pada penguat awal ini.

\section{TINJAUAN PUSTAKA}

\subsection{Tabung hampa trioda}

Ketika suatu logam (katoda) dipanaskan akan banyak terdapat elektron bebas dalam logam tersebut. Elektron tersebut dapat memancar melalui ruang hampa jika mendapat beda potensial listrik tertentu yang menghasilkan aliran arus, hal ini dikenal dengan Efek Edison [8]. Efek ini kemudian dikembangkan oleh John Ambrose Fleming yang menemukan Fleming Valve atau disebut dioda karena hanya memiliki dua elektroda. Dalam dioda hampa ditemukan bahwa jika katoda dipanaskan, elektron dapat mengalir dari katoda ke anoda, sehingga arus listrik dapat mengalir satu arah tetapi tidak pada arah sebaliknya.

Tiga tahun kemudian Lee De Forest menemukan trioda, yaitu suatu tabung hampa dengan tiga elektroda. Ketiga elektroda tersebut terdiri dari katoda sebagai pemancar elektron, anoda sebagai penerima elektron dan kisi sebagai pengendali aliran elektron. Selain memberi tegangan antara kisi dan katoda $\left(V_{g k}\right)$, medan elektrik yang dihasilkan di dalam suatu trioda dapat dibentuk dengan memberi tegangan antara anoda dan katoda $\left(V_{a k}\right)$. Namun karena kisi diletakkan berdekatan dengan katoda maka untuk menghasilkan medan elektrik yang sama dibutuhkan tegangan anoda yang lebih besar.

Nisbah tegangan anoda dengan tegangan kisi untuk menghasilkan intensitas medan sama besar disebut dengan faktor penguatan atau mu dengan simbol $\mu$ [9]. Grafik karakteristik lainnya adalah grafik karakteristik anoda (anode characteristics), yang merupakan grafik perubahan tegangan anoda $\left(V_{a}\right)$ terhadap arus anoda $\left(I_{a}\right)$ pada beberapa nilai tegangan kisi $\left(V_{g}\right)$ berbeda. Gambar 1 merupakan contoh grafik karakteristik anoda pada trioda seri ECC83. Grafik ini berguna untuk menganalisa dan merancang untai trioda. Dalam analisa sinyal kecil, grafik ini digunakan untuk mendapatkan nilai-nilai parameter sinyal kecil yaitu hambatan anoda $\left(r_{a}\right)$, transkonduktans $\left(g_{m}\right)$, dan faktor penguatan $(\mu)$. 


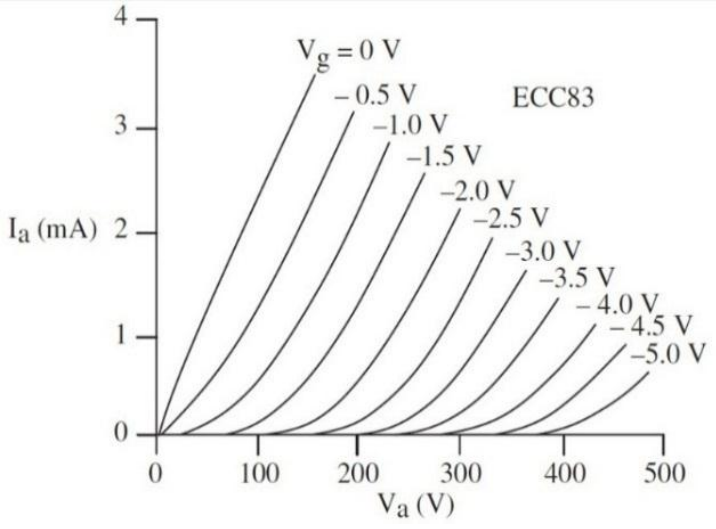

Gambar 1. Grafik Karakteristik Anoda ECC83.

Gambar 2 menunjukkan hambatan anoda $\left(r_{a}\right)$ disusun secara seri dengan anoda tabung, sementara catu daya anoda $\left(V_{A A}\right)$ digunakan untuk menyediakan tegangan positif dari anoda. Catu prategangan kisi $\left(V_{G G}\right)$ menjaga agar kisi selalu bernilai lebih negatif dari katoda. Untai tersebut akan menghasilkan nilai arus anoda $\left(I_{a}\right)$ tertentu. Di mana arus anoda tersebut akan menghasilkan tegangan jatuh sebesar $I_{a} \times r_{a}$ pada resistor anoda.

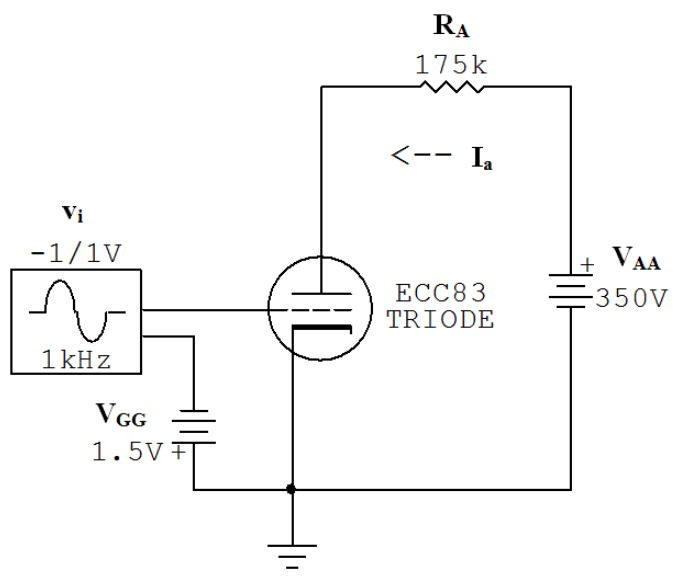

Gambar 2. Untai penguat sederhana trioda.

\subsection{Topologi untai trioda}

Topologi topologi katoda bersama merupakan topologi penguat tabung hampa yang paling sering digunakan sebagai penguat tegangan [9]. Untai penguat dengan topologi katoda bersama yang telah disederhanakan dengan hanya menunjukkan untai isyarat ac dapat dilihat pada Gambar 3.

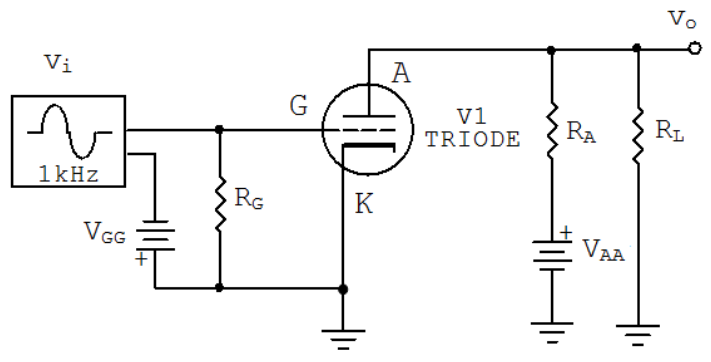

Gambar 3. Untai penguat katoda bersama.

Penguat ini memiliki nilai bati mendekati 1 , dan sering digunakan sebagai transformer penurun impedansi (step-down impedance transformer) ataupun sebagai penyangga [9]. Untai penguat, yang telah disederhanakan dengan hanya menunjukkan untai isyarat ac, menggunakan topologi anoda bersama dapat dilihat pada Gambar 4.

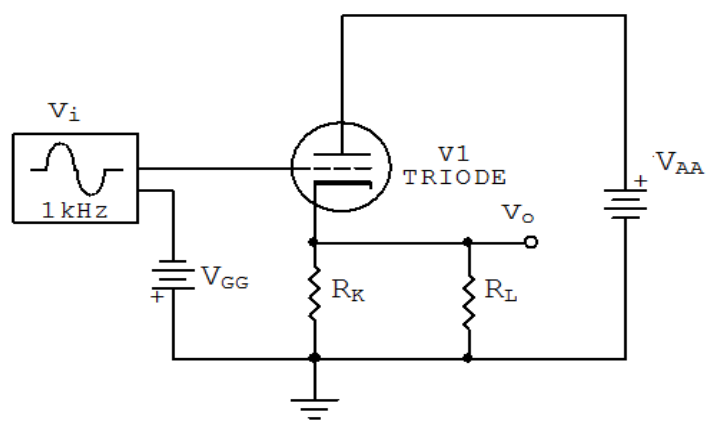

Gambar 4. Untai penguat anoda bersama.

\section{METODOLOGI PENELITIAN}

Tahapan penelitian dimulai dengan membuat grafik karakteristik tabung hampa pada tegangan rendah. Dari grafik karakteristik tabung hampa tersebut akan didapat parameter sinyal kecil yang kemudian digunakan untuk merancang penguat tabung hampa. Terdapat dua jenis grafik karakteristik tabung hampa yang digunakan dalam perancangan penguat, yaitu grafik karakteristik alih dan grafik karakteristik anoda.

\subsection{Grafik karakteristik pada aras rendah}

Grafik karakteristik alih merupakan fungsi tegangan kisi-katoda $\left(V_{G K}\right)$ terhadap arus anoda ( $\left.I_{a}\right)$ [10]. Sedangkan grafik karakteristik anoda merupakan grafik fungsi tegangan anoda-katoda $\left(V_{A K}\right)$ terhadap arus anoda $\left(I_{a}\right)$ dengan beberapa 
variasi tegangan kisi $\left(V_{G}\right)$. Grafik karakteristik tabung hampa dapat ditemukan dalam lembar data tabung hampa pada masing-masing serinya. Namun karena tabung hampa pada umumnya bekerja pada aras tegangan tinggi maka grafik karakteristik yang tersedia pada lembar data juga pada aras tegangan tinggi. Karena tabung hampa akan dikerjakan pada aras tegangan rendah maka perlu untuk melakukan pengukuran grafik karakteristik tabung hampa pada aras tegangan rendah. Gambar 5 dan 6 menunjukkan hasil pengukuran grafik karakteristik anoda dan alih tabung hampa pada aras tegangan rendah.

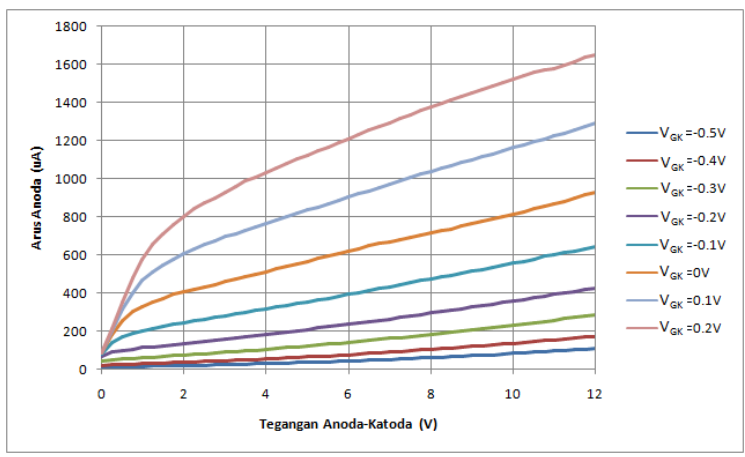

Gambar 5. Grafik karakteristik anoda tabung hampa 12AT7 pada aras tegangan rendah.

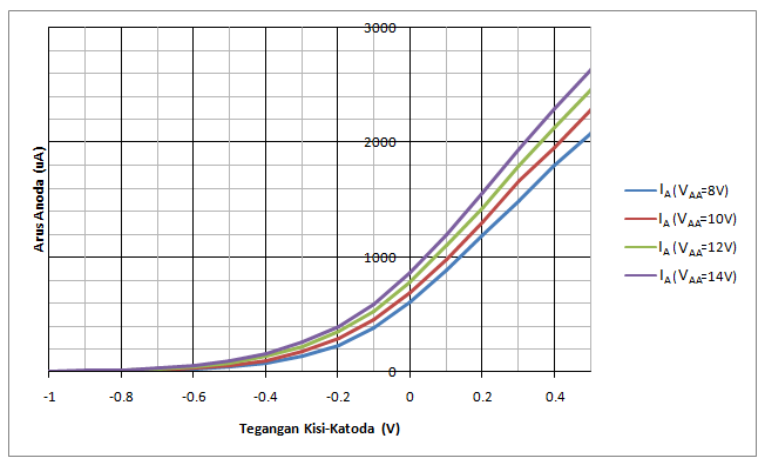

Gambar 6. Grafik karakteristik alih tabung hampa 12AT7 pada aras tegangan rendah.

\subsection{Perancangan untai penguat}

Perancangan dimulai dengan menentukan tegangan prasikap penguat, yang berupa tegangan searah (DC), meliputi penentuan titik kerja dan garis beban untai. Agar dapat diperoleh simpangan maksimum pada keluaran, tegangan titik kerja umumnya bernilai setengah dari nilai tegangan catu. Namun grafik karakteristik anoda pada Gambar 5 menunjukkan bahwa akan terjadi ketidak-linieran karakteristik anoda pada tegangan anoda-katoda $\left(V_{A K}\right)$ antara $0-2 \mathrm{~V}$. Sehingga titik kerja dipilih di tengah rentang daerah yang dianggap cukup linier antara $2-12$ $\mathrm{V}$, yaitu $7 \mathrm{~V}$. Grafik karakteristik alih pada Gambar 6 menunjukkan bahwa tabung hampa memiliki linearitas hanya pada rentang yang kecil. Karena isyarat masukan besarnya dibatasi hingga $0.28 \mathrm{Vpp}(100 \mathrm{mVrms})$ maka titik kerja dapat diletakkan pada rentang $V_{G K}=-0,225 \mathrm{~V}$ hingga $V_{G K}=0,075 \mathrm{~V}$. Penentuan tersebut didasarkan pada pendekatan linearitas grafik karakteristik alih yang ditunjukkan pada Gambar 7. Batasan-batasan tersebut dapat digunakan untuk menentukan titik kerja pada $V_{G K}=-0.075$ $\mathrm{V}$ dengan tegangan anoda-katoda pada $7 \mathrm{~V}$, sehingga menghasilkan arus anoda sebesar 500 $\mu \mathrm{A}$.

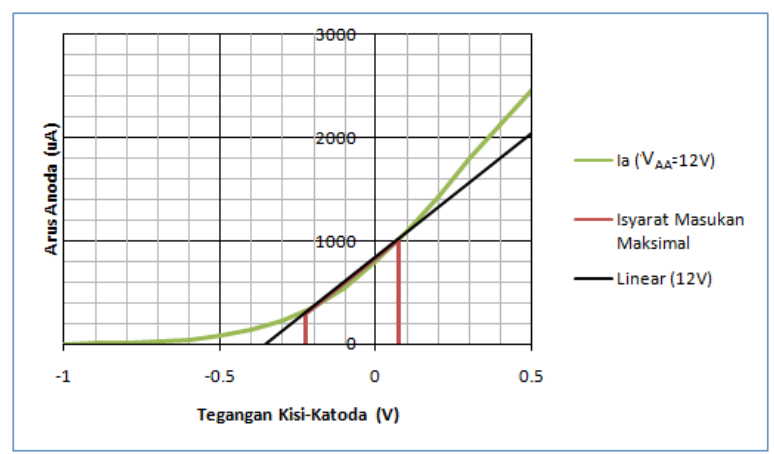

Gambar 7. Pendekatan linearitas pada grafik karakteristik alih.

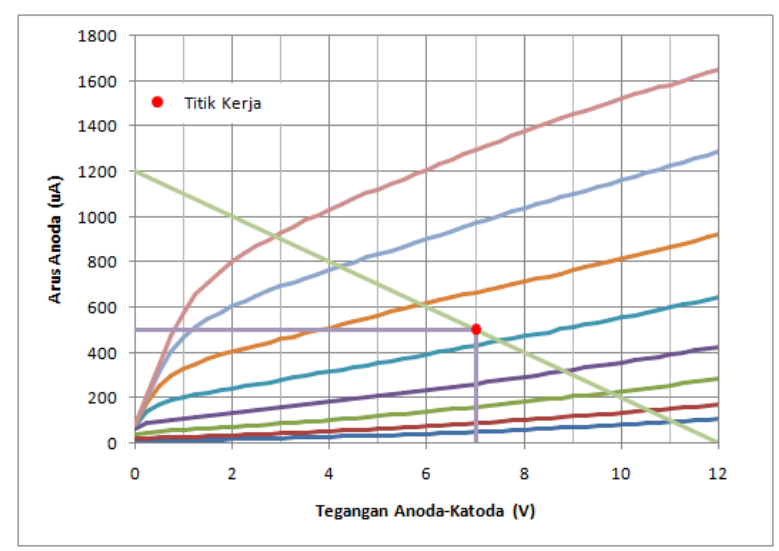

Gambar 8. Titik kerja penguat pada grafik karakteristik anoda.

Setelah didapat titik kerja penguat seperti ditunjukkan pada Gambar 8, maka akan diketahui nilai $r_{a}, g_{m}$, dan $\mu$ yaitu masing-masing $22613 \Omega, 2340 \mu \mathrm{A} / \mathrm{V}$, dan 52,91. Untai penguat 
tabung hampa menggunakan topologi penguat katoda bersama yang dikaskade dengan penguat anoda bersama seperti ditunjukkan pada Gambar 9. Penguat katoda bersama digunakan untuk mencapai spesifikasi penguatan. Sementara penguat anoda bersama digunakan untuk mencapai spesifikasi hambatan keluaran.

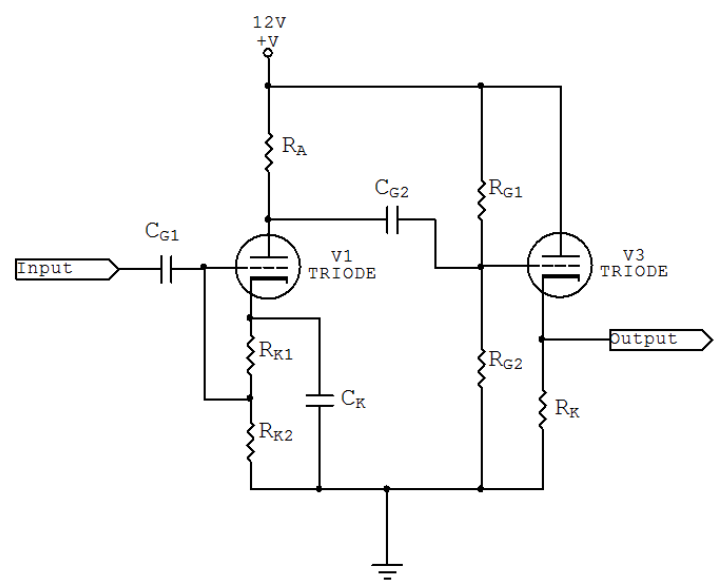

Gambar 9. Untai penguat awal tabung hampa.

Pada perancangan penguat katoda bersama, setelah diketahui nilai $\mu$ dan $r_{a}$, dan jika diinginkan penguatan minimal sebesar $21,7 \mathrm{~dB}$ maka dapat dicari nilai minimal $R_{A} \| R_{L}$, yaitu:

$$
\left(R_{A} \| R_{L}\right) \geq \frac{A_{v} \times R_{a}}{\mu\left(1-\frac{A_{v}}{\mu}\right)}
$$

Sehingga didapat nilai minimal $R_{A} \| R_{L}$ sebesar $6849,05 \Omega$. Maka dengan menggunakan $R_{A}$ sebesar $8500 \Omega$, akan didapat penguatan sebesar -13.105 kali (22.35 dB dengan isyarat membalik). Nilai impedansi keluaran untai anoda bersama adalah:

$$
Z_{\text {out }}=R_{K} \| \frac{r_{a}}{1+\mu}
$$

Jika bias kisi akan diletakkan pada nilai yang sama seperti pada perancangan untai katoda bersama sehingga $r_{a}, g_{m}$, dan $\mu$ memiliki nilai yang sama pula. Sehingga didapat nilai $r_{a} /((1+\mu))$ $=419.46 \Omega$, untuk berapapun nilai $R_{K}$, akan didapat impedansi keluaran akan selalu $<1 \mathrm{k} \Omega$. Sementara untuk bati tegangan dari untai anoda bersama nilainya selalu kurang dari $1(0 \mathrm{~dB})[10]$.

$$
A_{v}=\frac{\mu}{\frac{r_{a}}{R_{K}}+1+\mu}
$$

Jika digunakan $R_{K}$ sebesar $30 \mathrm{k} \Omega$ maka nilai penguatan untai anoda bersama menurut $\left.\begin{array}{llllll}\text { persamaan } & 3 & \text { sebesar } & 0,967 & (-0.28 & \mathrm{dB}\end{array}\right)$. Sementara penguatan total yang didapat yaitu sebesar $22.06 \mathrm{~dB}$.

\subsection{Perancangan untai penentu tanggapan frekuensi}

Untai penentu tanggapan frekuensi penguat awal dibagi menjadi dua bagian, yaitu tanggapan frekuensi bawah dan tanggapan frekuensi atas. Untai penentu tanggapan frekuensi bawah dirancang dengan memanfaatkan kapasitor pelewat (bypass) katoda $\left(C_{K}\right)$ yang membentuk tapis lolos atas (high-pass filter) pada penguat tabung hampa. Spesifikasi menuntut penguat awal memiliki frekuensi penggal bawah pada 20 $\mathrm{Hz}$, sehingga perhitungan untuk menentukan $C_{K}$ adalah sebagai berikut:

$$
C_{K}=\frac{R_{A}+r_{a}+\left(R_{K 1}+R_{K 2}\right)(1+\mu)}{2 \pi f_{L}\left(R_{A}+r_{a}\right)\left(R_{K 1}+R_{K 2}\right)}
$$

Akan digunakan $R_{K 1}$ sebesar $156 \Omega$ dan $R_{K 2}$ sebesar $1350 \Omega$, sehingga didapat $C_{K}$ sebesar 19.1 $\mu \mathrm{F}$. Namun karena nilai tersebut tidak tersedia di pasaran maka akan digunakan $C_{K}$ sebesar $22 \mu \mathrm{F}$. Sehingga untai penguat awal memiliki frekuensi penggal bawah pada 17,35 $\mathrm{Hz}$.

Untai tapis lolos bawah dan penyangga ditunjukkan pada Gambar 10.

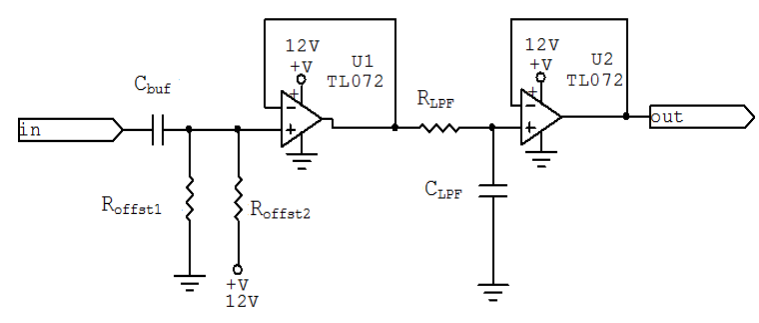

Gambar 10. Untai tapis lolos bawah dan penyangga.

Tapis lolos bawah memiliki frekuensi penggal atas $\left(f_{H}\right)$ yang ditentukan oleh kapasitor $C_{L P F}$ dan resistor $R_{L P F}$ dalam untai pada Gambar 10. Untai 
tapis dirancang agar memiliki frekuensi penggal atas pada $20 \mathrm{kHz}$ sehingga perhitungan untuk menentukan nilai $C_{L P F}$ adalah sebagai berikut:

$$
C_{L P F}=\frac{1}{2 \pi f_{H} R_{L P F}}
$$

Jika dipilih nilai $R_{L P F}$ sebesar $330 \Omega$, maka sesuai dengan persamaan 5 nilai $C_{L P F}$ yang digunakan sebesar 24,114 nF. Karena nilai tersebut tidak terdapat di pasaran, maka akan digunakan $C_{L P F}$ sebesar $22 \mathrm{nF}$ sehingga frekuensi penggal atas untai menjadi $21,9 \mathrm{kHz}$.

\subsection{Perancangan untai ragam cacat}

Untai ragam cacat akan digunakan untuk memberi warna suara (efek) pada gitar elektrik. Untai ragam cacat yang digunakan berupa efek flanger. Distorsi yang dihasilkan efek flanger akan membuat isyarat audio terdengar seperti pesawat jet yang melintas atau swooshing [11]. Flanger merupakan efek audio yang dihasilkan dari campuran dua isyarat yang sama dimana salah satu isyarat ditunda dengan waktu tundaan yang kecil dan berubah secara periodik [12]. Hubungan masukan-keluaran pada sistem flanger dapat dituliskan sebagai berikut.

$$
y(t)=x(t)+g x\{t-M(t)\}
$$

Di mana $g$ merupakan penguatan dari isyarat yang tertunda, hal ini akan menetukan intensitas atau 'kedalaman' (depth) dari efek flanger. Karena waktu tundaan $M$ berubah secara periodik, maka waktu tundaan dituliskan sebagai $M(t)$. Dalam ranah frekuensi sistem pada persamaan 5 akan menghasilkan tapis sisir dengan frekuensi puncak dan lembah yang berubah terhadap waktu. Hal ini terjadi karena waktu tundaan $\mathrm{M}$ berubah terhadap waktu. Gambar 11 merupakan sistem dari efek flanger sederhana. Gambar 12 merupakan blok diagram untai dari efek flanger.

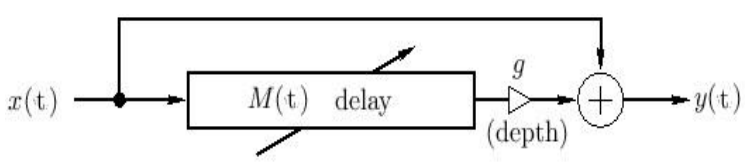

Gambar 11. Sistem flanger sederhana.
Dari blok diagram pada Gambar 12, sistem flanger terdiri dari 4 bagian utama yaitu untai penunda (delay line), osilator terkendali tegangan (voltage controlled oscillator/VCO), osilator frekuensi rendah (low frequency oscillator/ LFO), dan pencampur (mixer).

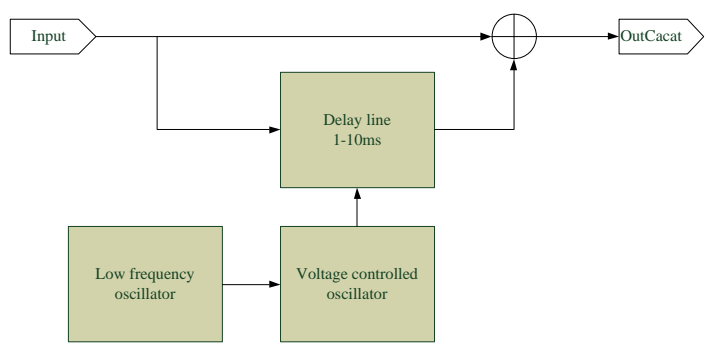

Gambar 12. Blok diagram efek flanger.

Untai penunda akan digunakan untuk menunda isyarat masukan untai flanger. Osilator terkendali tegangan berguna untuk menetapkan waktu tundaan pada untai penunda. Osilator frekuensi rendah digunakan sebagai pengubah waktu tundaan yang ditetapkan oleh osilator terkendali tegangan. Sementara pencampur digunakan untuk mencampurkan dua isyarat, yaitu isyarat yang telah ditunda dengan isyarat masukan asli.

\section{HASIL DAN PEMBAHASAN}

Pengujian penguat awal meliputi pengujian bati tegangan $\left(A_{v}\right)$, tanggapan frekuensi, kepekaan, hambatan masukan, hambatan keluaran, dan THD. Pengujian penguat ini mengacu pada IEC Standard 268: Sound System Equipment yang diterbitkan oleh International Electrotechnical Commission [13]. Pengukuran bati tegangan dilakukan dengan memberikan penguat isyarat masukan sebesar $100 \mathrm{mVpp}$ pada frekuensi $1 \mathrm{kHz}$ [13]. Isyarat masukan dipilih sebesar $100 \mathrm{mVpp}$ karena merupakan aras keluaran transducer instrumen musik [14]. Dari hasil pengukuran penguat memiliki bati sebesar 10.1 kali $(20,08 \mathrm{~dB})$ pada kanal kanan dan 10 kali $(20 \mathrm{~dB})$ pada kanal kiri. Kepekaan merupakan nilai amplitudo isyarat masukan suatu penguat yang menghasilkan isyarat keluaran maksimum penguat tersebut [15]. Pengujian kepekaan penguat dilakukan dengan memberikan isyarat masukan dengan amplitudo yang makin besar hingga isyarat keluaran 
penguat memiliki nilai THD 5\%. Nilai THD tersebut berdasarkan spesifikasi THD pada penguat awal yaitu $<5 \%$. Dari hasil pengukuran diperoleh bahwa kepekaan penguat sebesar 213 mVrms pada kanal kanan dan 212 mVrms pada kanal kiri. Dari hasil pengukuran hambatan masukan didapat nilai $r_{\text {in }}$ pada kanal kanan dan kiri sebesar 1112,84 k $\Omega$. Sementara hambatan

keluaran penguat tabung hampa sebesar $3535,97 \Omega$ pada kanal kanan dan $3192,97 \Omega$ pada kanal kiri. Tanggapan frekuensi diuji dengan menggunakan perangkat lunak CLIOwin dengan isyarat uji derau putih, karena isyarat derau putih memiliki daya yang sama besar pada seluruh jangkauan frekuensi audio [16].

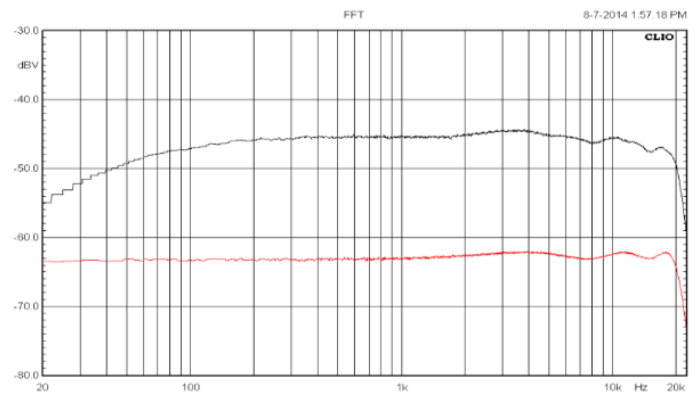

(a)

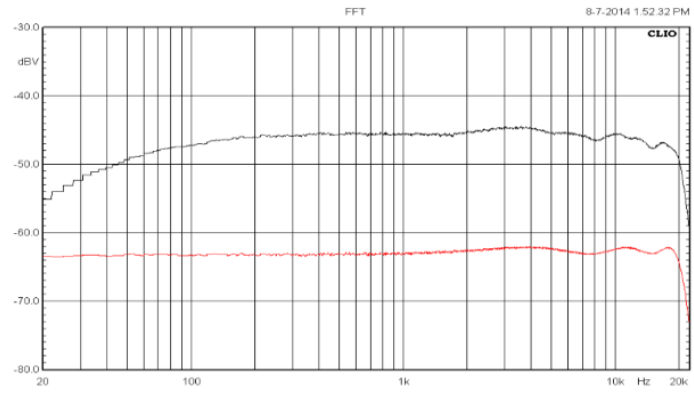

(b)

Gambar 13. Tanggapan frekuensi penguat pada ragam linier (a) kanal kanan. (b) kanal kiri.

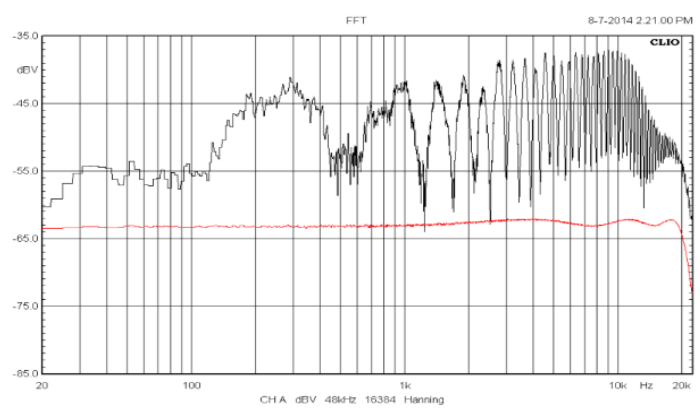

Gambar 14. Tanggapan frekuensi penguat pada ragam cacat.
Gambar 13(a) dan (b) menunjukkan hasil pengujian tanggapan frekuensi penguat awal pada kanal kiri dan kanan di mana garis merah merupakan isyarat uji berupa derau putih dan garis hitam merupakan isyarat keluaran dari penguat awal. Dari hasil pengukuran didapat bahwa penguat awal memiliki frekuensi penggal bawah pada $60 \mathrm{~Hz}$ dan frekuensi penggal atas pada $20 \mathrm{kHz}$. Untuk ragam cacat, tanggapan frekuensi efek flanger akan menghasilkan tapis sisir (comb filter). Gambar 14 menunjukkan tanggapan frekuensi dari penguat ragam cacat. Pada pengukuran ini, THD penguat akan diukur menggunakan fungsi multimeter pada perangkat lunak CLIOwin. Isyarat uji berupa isyarat sinus yang dibangkitkan oleh perangkat lunak CLIOwin. Dari Gambar 15 terlihat bahwa THD maksimal penguat terjadi pada kanal kanan di frekuensi $4 \mathrm{kHz}$, yaitu sebesar $1.7 \%$.

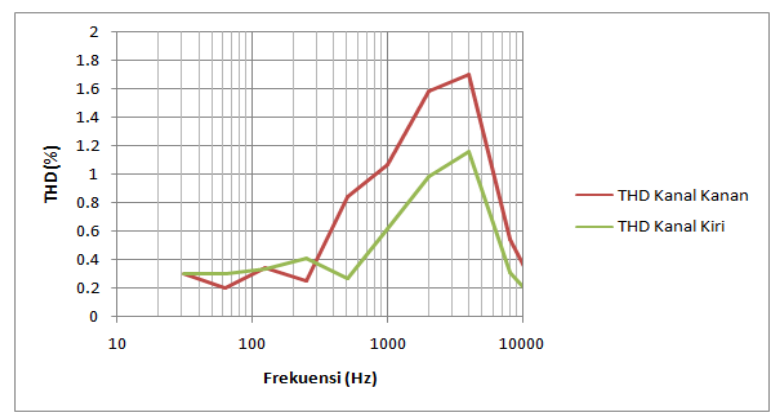

Gambar 15. THD penguat terhadap frekuensi.

\section{KESIMPULAN}

Penguat awal menggunakan tabung hampa pada aras tegangan rendah merupakan penguat yang memiliki kelebihan dibanding penguat transistor maupun penguat tabung hampa pada umumnya. Kelebihan tersebut adalah kepraktisan untai pada aras tegangan rendah dan kekhasan karakter suara tabung hampa. Penguat awal ini dapat digunakan untuk mereproduksi isyarat audio dari $60 \mathrm{~Hz}-20 \mathrm{kHz}$ dengan THD maksimal sebesar $1.7 \%$ pada ragam linier. Sementara pada ragam cacat memiliki tanggapan frekuensi tapis sisir yang akan menghasilkan efek flanger jika penguat awal ini digunakan sebagai penguat awal gitar elektrik. Spesifikasi penguat yang telah dibuat adalah sebagai berikut: impedansi masukan $>1 \mathrm{M} \Omega$, impedansi keluaran $<3.5 \mathrm{k} \Omega$, THD $<5 \%$ pada mode linier, penguatan 20,08 dB dan $20 \mathrm{~dB}$ pada kanal kanan dan kiri, serta kepekaan $212 \mathrm{mVrms.}$ 


\section{DAFTAR PUSTAKA}

[1] Rutt, T. E., Vacuum tube triode nonlinearity as part of the electric guitar sound, Convention of Audio Engineering Society, (1984).

[2] Aitchison, M. \& Fenton, S., Can transistors sound like valves?, Proceeding of Computing and Engineering Annual Researchers' Conference, pp. 20-26, (2010)

[3] Doidic, M., Mecca, M., M., Ryle, M., \& Senffer, C., U.S. Patent No. 5789 689, 1998.

[4] Hamm, R. O., Tubes vs transistors - Is there an audible difference?, Journal of the Audio Engineering Society, vol. 21 no. 4, pp. 267-273, (1973).

[5] Yeh, D. T., Automated Physical Modeling of Nonlinear Audio Circuits for Real-Time Audio Effects-Part II: BJT and Vacuum Tube Examples, IEEE Transactions on Audio, Speech, and Language Processing, vol. 4 no. 4, pp. 1207-1216, (2012).

[6] "Space-Charge and Other Low Voltage Tube", diakses dari http://www.junkbox.com/electronics/low voltagetubes.shtml, 16 Juni 2013.

[7] Jones, M., Valve amplifiers, ed. 3, Burlington: Linacre House, (2003).

[8] "The Edison Effect", diakses dari http://www.charlesedisonfund.org/tomedi sonbio/ch10.html, 28 Mei 2013.

[9] Ryder, J. D., Engineering electronics, ed. 2. New York: McGraw-Hill, (1957).

[10] Millman, J. \& Halkias, C. C., Integrated electronics, NewYork: McGraw-Hill, (1972).

[11] Celi, P., Get More Out of Your Flanger, diakses dari http://www.premierguitar.com/articles/G et_More_Out_of_Your_Flanger, magazine article, September 2012 edition, accessed July 21st, 2014

[12] Smith, J. O. Physical Audio Signal Processing, W3K Publishing, (2010).

[13] International Electrotechnical Commission, IEC Standard 268-3, Sound System Equipment - Part 3: Amplifiers, Geneva, Switzerland, (1988).

[14] Crown International Website, "FAQ: How to record direct? Please explain impedances and levels", diakses dari http://www.crownaudio.com/kb/entry/30 4/, (2014).

[15] Hi-Fi World "Sensitivity"., diakses dari http://www.hi-

fiworld.co.uk/amplifiers/75-amptests/150-sensitivity.html, (2014).

[16] Mutiarasari, Rina, "Pembangkit Derau Putih dan Merah Jambu untuk Pengujian Elektroakustik dan Audio", Salatiga, (2006).

\section{Biodata Penulis}

Dr. Matias H.W. Budhiantho, MSEE, menamatkan S1 di Universitas Kristen Satya Wacana (UKSW), Salatiga. Pendidikan S2 dan S3 diselesaikan di University of Texas at Austin, USA, berturut-turut pada tahun 1988 dan 1997 dengan bidang elektroakustika. Masuk sebagai dosen tetap di UKSW pada tahun 1974.

Gunawan Dewantoro, ST, M.Sc.Eng, lahir di Yogyakarta pada tahun 1985. Menamatkan pendidikan S1 di Teknik Elektro Universitas Gadjah Mada, Yogyakarta pada tahun 2008. Pendidikan S2 diselesaikan di National Taiwan University of Science and Technology pada tahun 2011 dengan bidang automasi dan kendali. Masuk sebagai dosen tetap di UKSW pada tahun 2012.

Demas Sabatino, ST, menerima gelar sarjana dari Fakultas Teknik Elektronika dan Komputer Universitas Kristen Satya Wacana (UKSW) Salatiga pada tahun 2014. Bidang keahliannya adalah teknik elektronika dan elektroakustika. 